\title{
Removal of Methylene Blue from Aqueous Solution Using Agricultural Residue Walnut Shell: Equilibrium, Kinetic, and Thermodynamic Studies
}

\author{
Ranxiao Tang, ${ }^{1}$ Chong Dai, ${ }^{2}$ Chao Li, ${ }^{1}$ Weihua Liu, ${ }^{1}$ Shutao Gao, ${ }^{1}$ and Chun Wang ${ }^{1}$ \\ ${ }^{1}$ College of Science, Agricultural University of Hebei, Baoding 071001, China \\ ${ }^{2}$ Department of Civil \& Environmental Engineering, University of Houston, Houston, TX 77004, USA \\ Correspondence should be addressed to Chun Wang; chunwang69@126.com
}

Received 15 December 2016; Revised 22 February 2017; Accepted 27 February 2017; Published 15 March 2017

Academic Editor: Khalid Z. Elwakeel

Copyright (C) 2017 Ranxiao Tang et al. This is an open access article distributed under the Creative Commons Attribution License, which permits unrestricted use, distribution, and reproduction in any medium, provided the original work is properly cited.

Walnut shell (WS), as an economic and environmental-friendly adsorbent, was utilized to remove methylene blue (MB) from aqueous solutions. The effects of WS particle size, solution $\mathrm{pH}$, adsorbent dosage and contact time, and concentration of $\mathrm{NaCl}$ on $\mathrm{MB}$ removal were systematically investigated. Under the optimized conditions (i.e., contact time $\sim 2 \mathrm{~h}, \mathrm{pH} \sim 6$, particle size $\sim 80$ mesh, dye concentration $20 \mathrm{mg} / \mathrm{L}$, and $1.25 \mathrm{~g} / \mathrm{L}$ adsorbent), the removal percentages can achieve $\sim 97.1 \%$, indicating WS was a promising absorbent to remove MB. Other supplementary experiments, such as Fourier transform infrared spectroscopy (FTIR), dynamic light scattering (DLS), and Brunauer-Emmett-Teller (BET) method, were also employed to understand the adsorption mechanisms. FTIR confirmed that the successful adsorption of MB on WS particles was through functional groups of WS. Using DLS method, the interactions between WS particles and dyes under various $\mathrm{pH}$ were investigated, which can be ascribed to the electrostatic forces. Kinetic data can be well fitted by the pseudo-second-order model, indicating a chemical adsorption. The adsorption isotherms were well described by both Langmuir and Freundlich models. Dubinin-Radushkevich model also showed that the adsorption process was a chemical adsorption. Thermodynamic data indicated that the adsorption was spontaneous, exothermic, and favorable at room temperature.

\section{Introduction}

Dyes have been widely used in various fields, such as textile, paper, rubber, plastic, leather, cosmetic, food, and drug industries. However, the extensive use of dyes produces a large amount of dye wastewater, which threatens our environment. What is more, most of the dyes or their metabolites are toxic and some of them are considered carcinogenic for human health $[1,2]$. Therefore, it is imperative to treat the dye wastewater before releasing it into the groundwater $[3,4]$.

The removal of dyes from wastewater has been extensively studied for decades, and many technologies have been developed, including oxidative degradation [5], biochemical degradation $[6,7]$, photodegradation $[8,9]$, electrocoagulation [10], electrochemical degradation [11], and adsorption $[12,13]$. Among these methods, adsorption has been found to be one of the most well-known and economic techniques for dye removal due to its easy operation, high efficiency, low cost, and recyclability [14]. Most recently, much attention has been paid to the development of crude biomass materials, such as peanut husk [15], coconut husk [16], potato peel [17], rice husk [18], and pomegranate peel [19], for the removal and separation of dyes from the wastewater.

Walnut shell (WS), as an abundant agricultural by-product, has good chemical stability and mechanical strength. Meanwhile, WS can be easily grinded into particles with desired particle sizes, and grinded WS has been demonstrated to be an effective absorbent for the removal of organic pollutants [20], heavy metals [21, 22], malachite green [23], and reactive brilliant red (K-2BP) [24]. However, to the best of our knowledge, few studies have been conducted to utilize walnut shells (WS) to remove methylene blue (MB) from aqueous solution. In this study, WS was used to investigate its capabilities to remove methylene blue (MB) from the aqueous 
solution for the first time, aiming to develop the efficient and low-cost treatment of methylene blue as well as promote the resource utilization of walnut shell.

To fill these information gaps, the objectives of this study were 3-fold: (1) batch adsorption experiments were conducted to measure the removal percentages of $\mathrm{MB}$ by WS particles with different sizes, in order to find the most effective WS particles for removing MB from aqueous solution; (2) batch adsorption experiments were conducted to systematically study the effects of $\mathrm{pH}$, contact time, adsorbent dosage, and initial dye concentration on MB removal; (3) batch adsorption experiments were carried out for the kinetic under various dye concentrations and thermodynamics studies under various temperatures. Thermodynamic parameters (e.g., $\Delta G, \Delta H$, and $\Delta S$ ) were calculated, and the results were analyzed to gain the mechanistic understanding of $\mathrm{MB}$ removal by WS under various experimental conditions. Some other supplementary techniques, including dynamic light scattering (DLS), Fourier transform infrared spectrometry (FTIR), and Brunauer-Emmett-Teller method (BET), were also utilized.

\section{Materials and Methods}

2.1. Preparation of Solutions. All the chemicals are of analytical grade. The stock solution of methylene blue (MB) $(0.5 \mathrm{~g} / \mathrm{L})$ was prepared in distilled water (DI water). The experimental solutions were prepared by diluting the stock solution with the distilled water to the desired concentrations (i.e., 20, 40, 60,80 , and $100 \mathrm{mg} / \mathrm{L}$ ).

2.2. Preparation of the Adsorbent. Walnut shells (WS) were washed with tap water multiple times, to remove dust and soluble impurities. Then, WS were rinsed with distilled water and dried in an oven at $105^{\circ} \mathrm{C}$ to constant weight. The dried and cleaned WS were grounded, sieved (20,60,80, and $120 \mathrm{mesh}$ ), and stored in a desiccator for further use.

2.3. Adsorbent Characterization. The chemical bonding states of WS, before and after MB adsorption, were measured by Fourier transform infrared spectrometry (FTIR) (WQF$520 \mathrm{~A})$. The specific surface areas of WS with different sizes $(20,60,80$, and 120 mesh) were measured by nitrogen adsorption using the Brunauer-Emmett-Teller method (VSorb2800). Dynamic light scattering (DLS, Zetasizer Nanoseries, Malvern Instruments) was used to measure the zeta potential values $(\zeta)$ of WS particles in aqueous solutions under various $\mathrm{pH}$ conditions [30,31]. According to previous work, the WS particles of $0.1 \mathrm{~g}$ were suspended in DI water ( $\mathrm{pH}$ was adjusted from 2 to 12 using $0.1 \mathrm{~mol} / \mathrm{L} \mathrm{HCl}$ or $\mathrm{NaOH}$ ), and the zeta potential measurements were conducted every $1 \mathrm{~min}$ for $30 \mathrm{~min}$. The average values and standard deviations of zeta potential values were calculated after the readings became stable $[32,33]$.

2.4. Batch Adsorption Experiments. Batch adsorption experiments were carried out by mixing a certain amount of $\mathrm{MB}$ particles with $20.0 \mathrm{~mL} \mathrm{MB}$ solution of desired concentrations

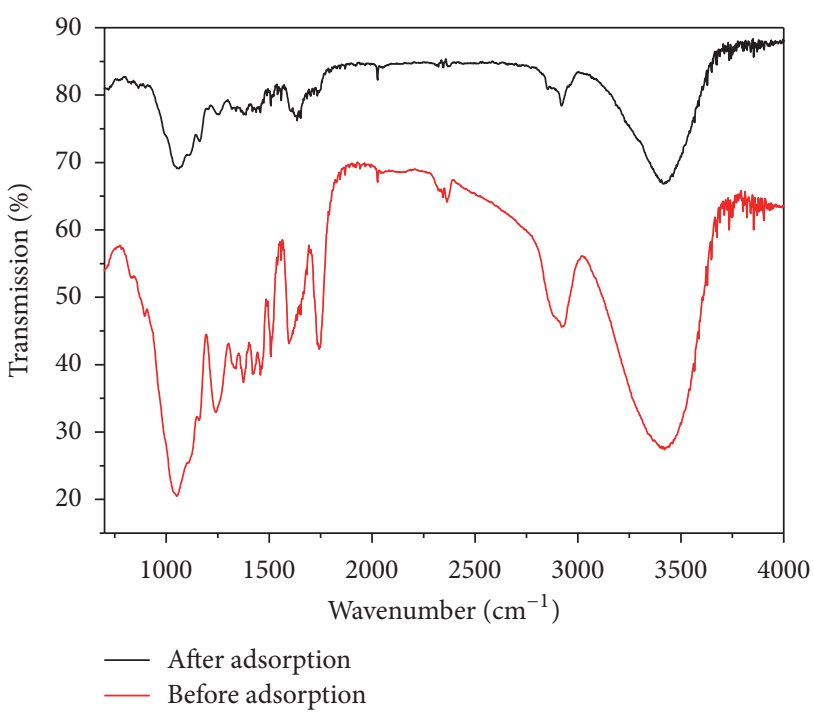

FIGURE 1: FTIR spectrum of walnut shell particles, before and after adsorption.

and then shaking on a platform shaker until the equilibrium was achieved. The effects of the WS particle sizes (20$120 \mathrm{mesh})$, adsorbent dosages $(0.10-2.50 \mathrm{~g} / \mathrm{L})$, contact time (0-120 min), initial $\mathrm{pH}$ (2-11), initial MB concentration (20-100 $\mathrm{mg} / \mathrm{L})$, concentration of $\mathrm{NaCl}(1,5$, and $10 \%)$, and temperature $(298,308,318$, and $328 \mathrm{~K})$ on the adsorption of $\mathrm{MB}$ on WS particles were also investigated. After adsorption experiments, the solutions were filtered and the MB concentrations in the supernatant were analyzed using a UV/VisDR 3900. The wavelength of $568 \mathrm{~nm}$ was chosen, where the maximum absorbance can be achieved.

The adsorption capacity $\left(q_{t}\right)$ and MB removal percentage $(R)$ were calculated as (1) and (2), respectively.

$$
\begin{aligned}
q_{t} & =\frac{c_{0}-c_{t}}{m} \times V \\
R & =\frac{c_{0}-c_{t}}{c_{0}} \times 100 \%,
\end{aligned}
$$

where $q_{t}(\mathrm{mg} / \mathrm{g})$ represents the adsorption capacity at time $t$; $c_{0}$ and $c_{t}(\mathrm{mg} / \mathrm{L})$ are the $\mathrm{MB}$ concentration at initial solution and at time $t(\mathrm{~min})$, respectively; $V(\mathrm{~L})$ is the volume of the solution; and $m(\mathrm{~g})$ is the weight of the WS particles.

\section{Results and Discussion}

3.1. Characterization of Walnut Shell. Figure 1 shows the FTIR spectrum of walnut shell before and after MB adsorption. Before $\mathrm{MB}$ adsorption, the spectrum contained several peaks, corresponding to $-\mathrm{OH}$ stretching (at $3422.5 \mathrm{~cm}^{-1}$ ), $\mathrm{C}-\mathrm{H}$ stretching (at $2923.7 \mathrm{~cm}^{-1}$ ), $\mathrm{C}=\mathrm{O}$ stretching (at 1739.0 $\mathrm{cm}^{-1}$ ), N-H bending (at $1631.4 \mathrm{~cm}^{-1}$ ), $\mathrm{CH}_{2}$ deformation (at $1162.3 \mathrm{~cm}^{-1}$ ), and -COO symmetric stretching (at 1053.9 $\mathrm{cm}^{-1}$ ). After MB adsorption, the shifts of bands were observed: $-\mathrm{OH}$ stretching (at $3428.7 \mathrm{~cm}^{-1}$ ), C-H stretching (at $2936.1 \mathrm{~cm}^{-1}$ ), $\mathrm{C}=\mathrm{O}$ stretching (at $1745.3 \mathrm{~cm}^{-1}$ ), $\mathrm{N}-\mathrm{H}$ bending 
TABLE 1: BET- $\mathrm{N}_{2}$ specific surface area of walnut shell (WS) particles with different sizes.

\begin{tabular}{lcccc}
\hline Particle size $/$ mesh & 20 & 60 & 80 & 120 \\
\hline Surface $\operatorname{area} /\left(\mathrm{m}^{2} / \mathrm{g}\right)$ & 1.01 & 1.24 & 2.82 & 3.12 \\
\hline
\end{tabular}

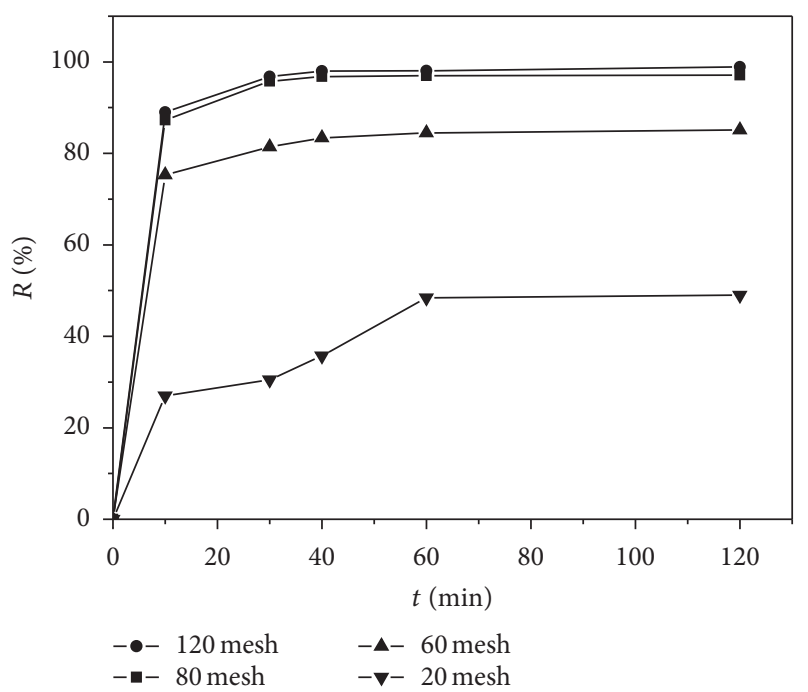

FIGURE 2: The effect of particle sizes on the adsorption of MB on WS. Conditions: temperature ( $298 \mathrm{~K}), \mathrm{MB}$ concentration $(20 \mathrm{mg} / \mathrm{L})$, and WS adsorbent dosage $(1.25 \mathrm{~g} / \mathrm{L})$.

(at $1601.6 \mathrm{~cm}^{-1}$ ), $\mathrm{CH}_{2}$ deformation (at $1240.2 \mathrm{~cm}^{-1}$ ), and -COO symmetric stretching (at $1047.7 \mathrm{~cm}^{-1}$ ). The shifts of these bands indicated $\mathrm{MB}$ adsorption onto WS was via functional groups of WS [34].

Table 1 shows the BET-N $\mathrm{N}_{2}$ specific surface area of WS particles with different sizes, which was obtained by $\mathrm{N}_{2}$ adsorption and desorption isotherm. Results showed that the surface area of WS increased with the decreasing of WS particle sizes.

3.2. Effect of Particle Size and Contact Time. At the contact time of $2 \mathrm{~h}$, the MB removal percentages (\%) of 120,80 , 60 , and 20 mesh particles were 98.9, 97.1, 85.1, and 49.0\%, respectively (Figure 2), indicating that $\mathrm{MB}$ removal percentage (\%) increased with the decreasing of WS particle sizes. As discussed earlier, the small particles had higher surface areas than the big particles, which contributed to more available adsorption active sites, thus resulting in higher removal percentages [35]. When the particle size of WS particles reached $\sim 80$ mesh, the removal percentage of MB on WS can achieve $97.1 \%$, which met the requirement of dye removal from wastewater $[16,19]$. When the particle sizes of WS particles were smaller than 80 mesh (i.e., 120 mesh), the dye removal percentages were similar as 80 mesh; therefore, the particles of 80 mesh were used for the rest of the experiments.

As shown in Figure 2, within the first $30 \mathrm{~min}$, for all particles, the adsorption capacities of MB on WS particles with different sizes significantly increased with the increased contact time. After $30 \mathrm{~min}$, the adsorption processes slowed down until the equilibrium was achieved after $2 \mathrm{~h}$ for all particles. Therefore, a contact time of $2 \mathrm{~h}$ was chosen as for

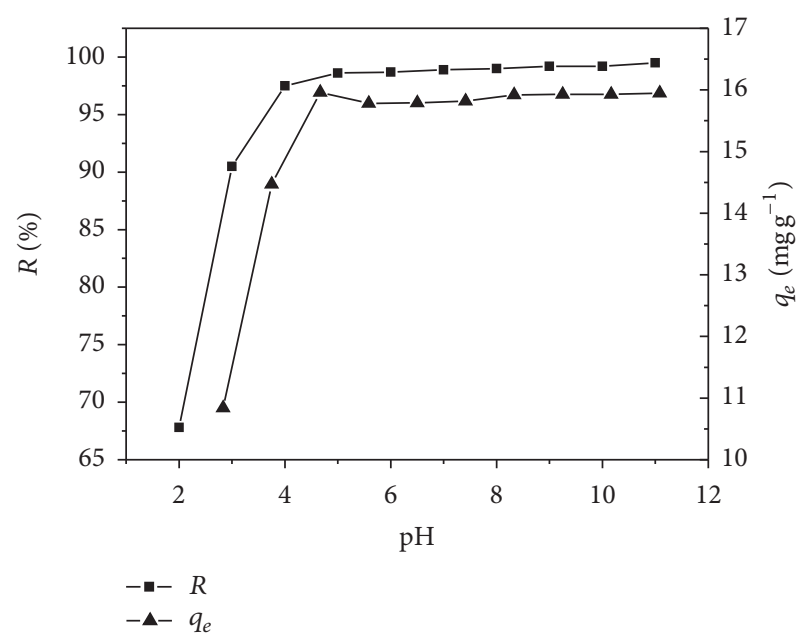

FIGURE 3: Effect of initial $\mathrm{pH}$ on MB adsorption (conditions: temperature $(298 \mathrm{~K})$, dye concentration ( $20 \mathrm{mg} / \mathrm{L})$, particle size ( $80 \mathrm{mesh}$ ), adsorbent dosage $(1.25 \mathrm{~g} / \mathrm{L})$, and contact time $(2 \mathrm{~h})$ ).

the following experiments. The adsorption of MB on WS particles occurred very rapidly during the first $30 \mathrm{~min}$ due to the sufficient available number of active sites at walnut shell surface; then the adsorption slowed down when the remaining active sites were less available until the equilibrium phase was achieved [36].

3.3. Effect of Initial $\mathrm{pH}$. The aqueous solution $\mathrm{pH}$ was found to significantly affect the adsorption capacities of dyes onto adsorbents [12]. Accordingly, the adsorption capacities of MB on WS were investigated under various aqueous solution $\mathrm{pH}$. Figure 3 shows that, under acidic conditions ( $\mathrm{pH}=2 \sim 5), \mathrm{MB}$ dye removal percentage (from 67.8 to $98.6 \%$ ) and $q_{e}$ (from 10.84 to $15.78 \mathrm{mg} / \mathrm{g}$ ) on WB increased significantly with $\mathrm{pH}$ increasing, while under base conditions $(\mathrm{pH}=6 \sim 11), \mathrm{MB}$ dye removal percentage (from 98.7 to $99.5 \%$ ) and $q_{e}$ (from 15.79 to $15.95 \mathrm{mg} / \mathrm{g}$ ) on WB were similar.

The differences in adsorption behavior under various $\mathrm{pH}$ values can be explained well from the electrostatic forces between the surface charge of WS particles and MB dyes. The zeta potentials $(\zeta)$ of WS under varying $\mathrm{pH}$ values are shown in Table 2. Results showed that the WS particles were all negatively charged under our $\mathrm{pH}$ conditions $(\mathrm{pH}=2 \sim$ 11). However, the WS surface was significantly less negatively charged at lower $\mathrm{pH}$ than at higher $\mathrm{pH}$. Therefore, there was less electrostatic attractive force between the dye cations and the adsorbent surface, which can result in lower adsorption capacity at lower $\mathrm{pH}$. Also, under acidic conditions, large amounts of $\mathrm{H}_{3} \mathrm{O}^{+}$ions existed, which can compete with dye cations adsorbing on the active sites of WS, resulting in the significant decreasing in the amount of adsorbed dye.

To sum up, the adsorption capacities of WS particles for $\mathrm{MB}$ were highly dependent on solution $\mathrm{pH}$. In order to get high removal rates of $\mathrm{MB}$ dyes, the $\mathrm{pH}$ of above 6 of aqueous solutions was suggested. The $\mathrm{pH}$ value of $\mathrm{MB}$ initial solution was measured to be $\sim 6.15$, and $\mathrm{MB}$ solutions without adjusting $\mathrm{pH}$ were used for studying the effect of adsorbent dosage as well as the kinetic and thermodynamic studies. 
TABLE 2: The zeta potentials of WS at different $\mathrm{pH}$.

\begin{tabular}{lcccccccccc}
\hline $\mathrm{pH}$ & 2.02 & 2.98 & 3.98 & 4.89 & 5.80 & 7.04 & 7.88 & 8.97 & 10.00 & 11.93 \\
\hline$\zeta / \mathrm{mV}$ & -4.217 & -12.19 & -18.51 & -22.99 & -23.15 & -24.96 & -25.01 & -25.18 & -26.68 & -33.68 \\
\hline
\end{tabular}

TABLE 3: Kinetic parameters for MB adsorption on WS.

\begin{tabular}{lcccccccccc}
\hline \multirow{2}{*}{$c_{0} / \mathrm{mg} / \mathrm{L}$} & $q_{e}$, exp/mg/g & \multicolumn{3}{c}{ Pseudo-first order equation } & \multicolumn{2}{c}{ Pseudo-second order equation } & \multicolumn{3}{c}{ Intraparticle diffusion model } \\
& & $R^{2}$ & $q_{e}, \mathrm{cal} / \mathrm{mg} / \mathrm{g}$ & $k_{1} / \mathrm{g} / \mathrm{mg} \cdot \mathrm{min}$ & $R^{2}$ & $q_{e}, \mathrm{cal} / \mathrm{mg} / \mathrm{g}$ & $k_{2} / \mathrm{g} / \mathrm{mg} \cdot \mathrm{min}$ & $R^{2}$ & $C / \mathrm{mg} / \mathrm{g}$ & $k_{3} / \mathrm{mg} / \mathrm{g} \cdot \mathrm{min}{ }^{1 / 2}$ \\
\hline 20 & 15.70 & 0.697 & 0.310 & 0.0290 & 1.000 & 15.72 & 0.097 & 0.778 & 14.91 \\
40 & 28.88 & 0.748 & 2.494 & 0.0223 & 0.998 & 28.99 & 0.025 & 0.843 & 25.67 & 0.074 \\
60 & 40.52 & 0.011 & 0.865 & 0.0039 & 1.000 & 40.49 & 0.102 & 0.336 & 39.46 & 0.097 \\
80 & 48.22 & 0.567 & 5.733 & 0.0316 & 0.998 & 48.31 & 0.013 & 0.191 & 45.22 & 0.196 \\
100 & 48.77 & 0.676 & 3.645 & 0.0129 & 1.000 & 48.08 & 0.020 & 0.710 & 43.32 & 0.471 \\
\hline
\end{tabular}

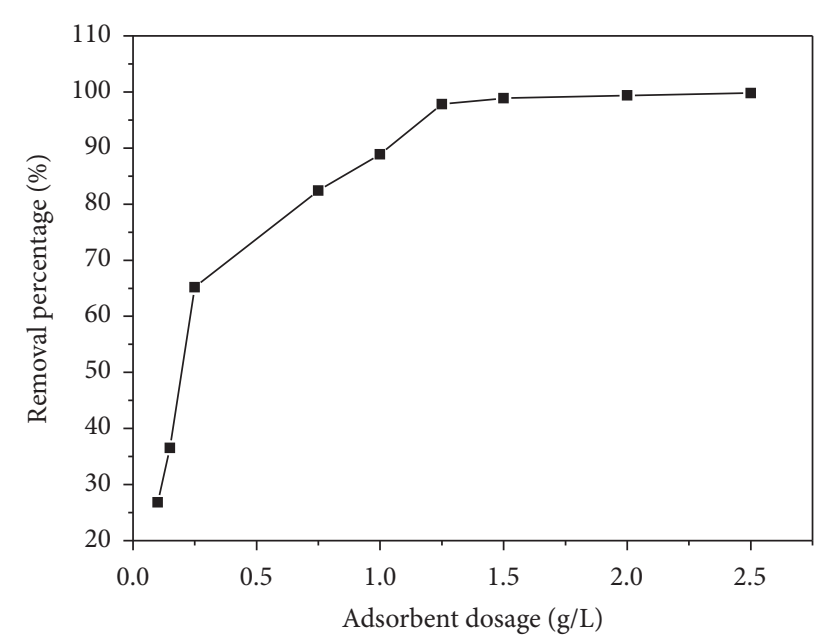

FIGURE 4: Effect of adsorbent dosage on the adsorption of MB by WS particles. Conditions: temperature $(298 \mathrm{~K})$, dye concentration $(20 \mathrm{mg} / \mathrm{L})$ and particle size ( $80 \mathrm{mesh})$, and contact time $(2 \mathrm{~h})$.

3.4. Effect of Adsorbent Dosage. The effect of walnut shell dosage on the MB removal percentage (\%) was examined for a contact time of $2 \mathrm{~h}$. As shown in Figure 4, MB dye removal percentage (\%) at equilibrium increased from 26.8 to $99.8 \%$ with the increasing of the adsorbent dosage from 0.10 to $1.25 \mathrm{~g} / \mathrm{L}$. Above $1.25 \mathrm{~g} / \mathrm{L}$ of adsorbent dose, the dye removal percentage did not significantly improve, which indicated that the removal percentage of MB by WS particles reached an optimal value at $1.25 \mathrm{~g} / \mathrm{L}$. With the increasing of adsorbent dosage, more adsorption sites are available. When the adsorption equilibrium was reached, all the available adsorption sites of WS particles were almost saturated with $\mathrm{MB}$; therefore, any further increase of adsorbent dose only slightly affected the removal percentage of $\mathrm{MB}$ by WS particles. Accordingly, considering both the high removal percentage and low cost, the optimal adsorbent dose value of $1.25 \mathrm{~g} / \mathrm{L}$ was selected to carry out the following kinetic and thermodynamic adsorption experiments.

3.5. Kinetic Analysis. The kinetic experiments were conducted at the optimal conditions $(\mathrm{pH} \sim 6,1.25 \mathrm{~g} / \mathrm{L}$ WS particles with 80 mesh, and contact time of $2 \mathrm{~h}$ ) under various dye concentrations (i.e., 20, 40, 60, 80 , and $100 \mathrm{mg} / \mathrm{L}$ ). The kinetics of $\mathrm{MB}$ adsorption onto WS particles were investigated using three common models, being pseudo-first-order model (3), pseudo-second-order model (4), and intraparticle diffusion model (5), respectively.

$$
\begin{aligned}
\log \left(q_{e}-q_{t}\right) & =\log q_{e}-\frac{k_{1} t}{2.303} \\
\frac{t}{q_{t}} & =\frac{1}{k_{2} q_{e}^{2}}+\frac{t}{q_{e}} \\
q_{t} & =k_{3} t^{1 / 2}+C,
\end{aligned}
$$

where $q_{t}(\mathrm{mg} / \mathrm{g})$ and $q_{e}(\mathrm{mg} / \mathrm{g})$ represent the adsorption capacities at time $t$ and at equilibrium, respectively; $k_{1}$ $(\mathrm{g} /(\mathrm{mg} \cdot \mathrm{min})), k_{2}(\mathrm{~g} /(\mathrm{mg} \cdot \mathrm{min}))$, and $k_{3}\left(\mathrm{~g} /\left(\mathrm{mg} \cdot \mathrm{min}^{1 / 2}\right)\right)$ are the first-order, second-order, and intraparticle diffusion rate constants, respectively; $C$ is the intercept of intraparticle diffusion model.

The fitting results are summarized in Figure 5 and Table 3. For all dye concentrations $(20,40,60,80$, and $100 \mathrm{mg} / \mathrm{L})$, the correlation for pseudo-second-order model $(>0.998)$ was much larger than that for the pseudo-first-order model $(<0.697)$, indicating that MB adsorption onto WS can be described as pseudo-second-order model. Furthermore, the adsorption capacities calculated by pseudo-second-order model were close to those determined by the experiments. Contrarily, the adsorption capacities calculated by pseudofirst-order model were quite different with the experimental data. Therefore, we concluded that MB adsorption on WS can be described as pseudo-second-order model, which indicated that the adsorption of $\mathrm{MB}$ on WS can be described as chemical adsorption $[18,37]$.

For the intraparticle diffusion model, none of the regions has $C$ values equal to zero, indicating that these lines did not pass through the origins. This suggested that intraparticle diffusion was present but may not be the rate limiting step [38].

3.6. Adsorption Isotherms. Three commonly used models (i.e., Langmuir, Freundlich, and Dubinin-Radushkevich (D$\mathrm{R})$ ) were utilized to analyze the adsorption isotherms of $\mathrm{MB}$ 


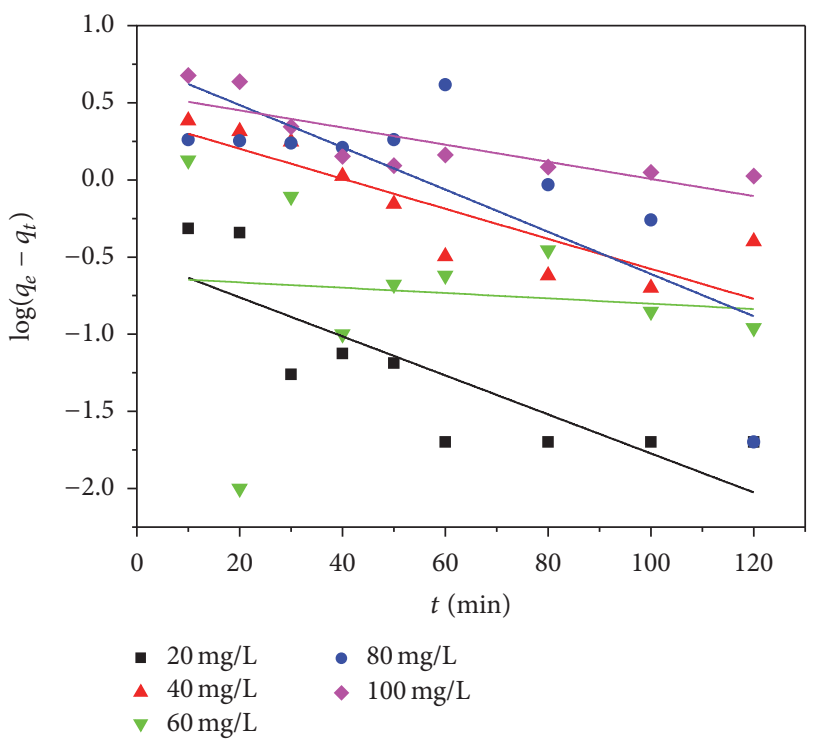

(a)

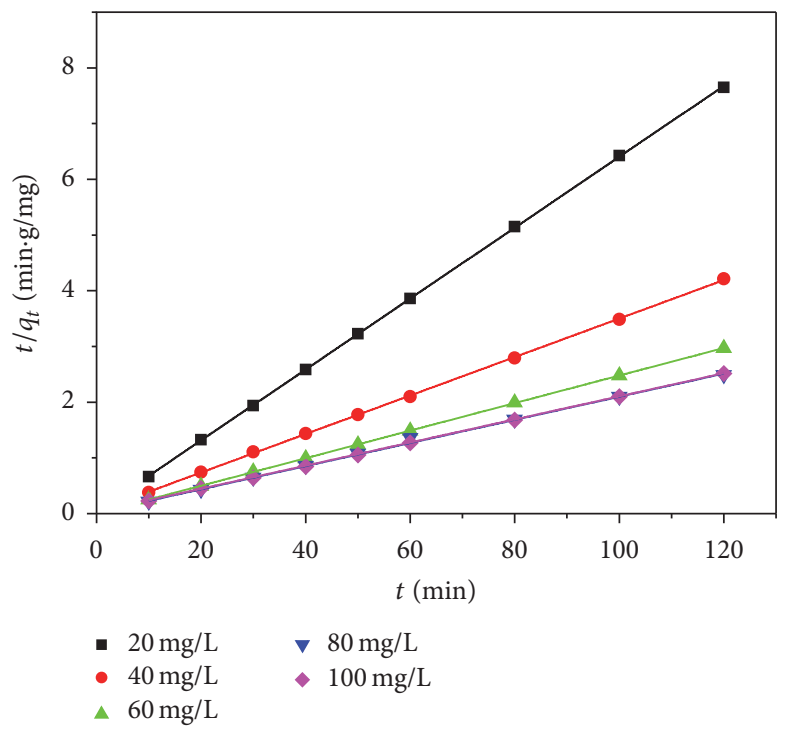

(b)

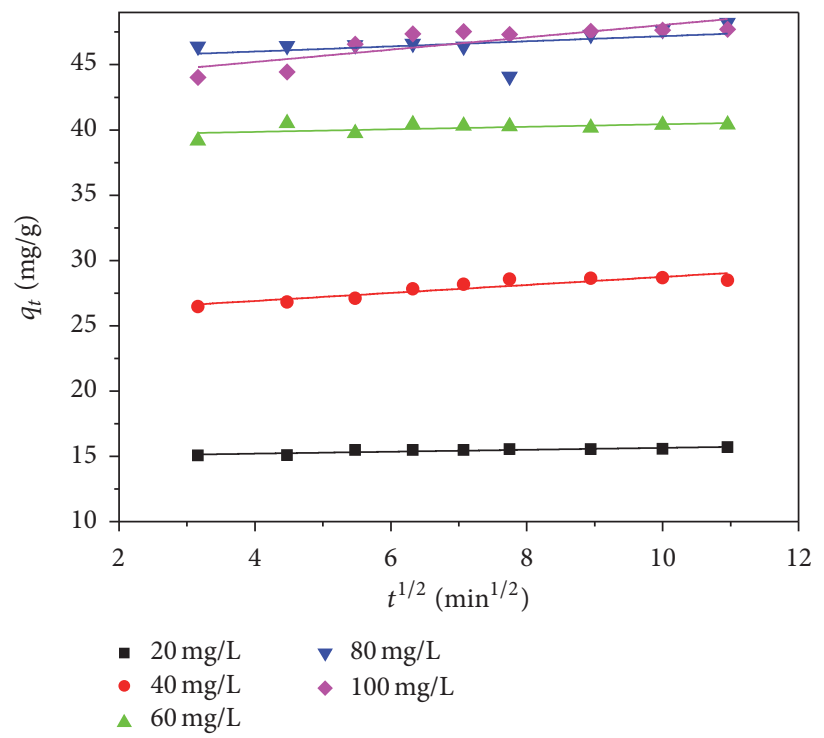

(c)

FIGURE 5: Kinetic curves for MB adsorption on WS at various different concentrations: (a) pseudo-first-order model, (b) pseudo-second-order model, and (c) intraparticle diffusion of particles model.

on WS particles under varying temperature (i.e., 298, 308, 318, and $328 \mathrm{~K})$. The Langmuir model assumes that a monolayer adsorption on a surface with a finite number of identical sites occurred, all the sites are energetically equivalent, and there is no interaction between the adsorbed molecules [39]. The Freundlich model is a semiempirical equation based on the adsorption on a heterogeneous surface [40]. The D-R model is often used to determine whether a sorption process is chemical or physical sorption [41]. Equations (6)-(8) are mathematical models corresponding to these three sorption isotherms, respectively.

$$
\frac{c_{e}}{q_{e}}=\frac{c_{e}}{q_{\max }}+\frac{1}{K_{L} q_{\max }}
$$

$$
\begin{aligned}
& \ln q_{e}=\frac{1}{n} \ln c_{e}+\ln K_{F} \\
& \ln q_{e}=\ln q_{m}-\beta \varepsilon^{2},
\end{aligned}
$$

where $q_{\max }$ is the maximum adsorption capacity at equilibrium $(\mathrm{mg} / \mathrm{g}) ; K_{L}$ is the Langmuir constant reflecting the energy of the adsorption $(\mathrm{mg} / \mathrm{L}) ; K_{F}$ is Freundlich constant implying sorption intensity; $1 / n$ is Freundlich constant indicating the adsorption capacity; $\beta$ is coefficient relating to the mean free energy during sorption process; $\varepsilon$ is the Polanyi potential and $\varepsilon=R T \ln \left(1+1 / c_{e}\right)$. The activation energy $\left(E_{a}\right)$ can be computed using the following relationship:

$$
E_{a}=\frac{1}{\sqrt{2 \beta}}
$$


TABLE 4: Adsorption parameters of methylene blue on the walnut shell powder at different temperatures.

\begin{tabular}{|c|c|c|c|c|c|}
\hline \multirow{2}{*}{ Isotherm } & \multirow{2}{*}{ Parameter } & \multicolumn{4}{|c|}{$T / \mathrm{K}$} \\
\hline & & 298 & 308 & 318 & 328 \\
\hline \multirow{3}{*}{ Langmuir } & $R^{2}$ & 0.999 & 0.979 & 0.971 & 0.987 \\
\hline & $q_{\max } / \mathrm{mg} \cdot \mathrm{g}^{-1}$ & 51.55 & 49.83 & 56.13 & 55.96 \\
\hline & $K_{L} / \mathrm{L} \cdot \mathrm{mg}^{-1}$ & 0.419 & 0.181 & 0.163 & 0.119 \\
\hline \multirow{3}{*}{ Freundlich } & $R^{2}$ & 0.981 & 0.972 & 0.963 & 0.987 \\
\hline & $K_{F}$ & 18.80 & 15.86 & 13.00 & 10.50 \\
\hline & $1 / n$ & 0.270 & 0.323 & 0.357 & 0.464 \\
\hline \multirow{2}{*}{ D-R } & $R^{2}$ & 0.987 & 0.998 & 0.989 & 0.995 \\
\hline & $E_{a} / \mathrm{kJ} \cdot \mathrm{mol}^{-1}$ & 16.13 & 22.44 & 12.64 & 15.15 \\
\hline
\end{tabular}

TABLE 5: Thermodynamic parameters for the adsorption of MB on WS.

\begin{tabular}{lccc}
\hline$T / \mathrm{K}$ & $\Delta G /(\mathrm{kJ} / \mathrm{mol})$ & $\Delta H /(\mathrm{kJ} / \mathrm{mol})$ & $\Delta S(\mathrm{~J} / \mathrm{mol} \cdot \mathrm{K})$ \\
\hline 298 & -3.78 & & -29.71 \\
308 & -2.75 & -12.22 & \\
318 & -2.13 & & -2.08 \\
328 & -2.08 & \\
\hline
\end{tabular}

Adsorption isotherms of MB on WS are summarized in Figure 6 and Table 4. The isotherms fitted well with both the Langmuir and the Freundlich models. The value of $q_{\max }$ and $K_{F}$ for the adsorption decreased with the increasing of temperature, indicating that the adsorption of MB on WS particles was exothermic. According to the literature, when $0.1<1 / n \leq 0.5$, adsorption is easy; when $0.5<1 / n \leq 1$, the adsorption is difficult; when $1 / n>1$, the adsorption is quite difficult [42]. In this study, the $1 / n$ values were in the range of 0.102 to 0.464 , indicating that the MB could be easily adsorbed by walnut shell particles. For the D-R model, the $E_{a}$ value can be used to evaluate the sorption properties. If $E_{a}>8 \mathrm{~kJ} / \mathrm{mol}$, there must be a chemical reaction; then if $E_{a}<8 \mathrm{~kJ} / \mathrm{mol}$, there must be a physical adsorption [41]. In our experiments, through D-R isotherm simulation, the $E_{a}$ values of MB adsorption on WS particles were 12.64 22.44 kJ/mol, implying that the main mechanism for the adsorption was a chemical reaction.

3.7. Thermodynamic Parameters. Thermodynamic parameters (i.e., Gibbs free energy $(\Delta G)$, enthalpy $(\Delta H)$, and entropy $(\Delta S))$ of $\mathrm{MB}$ adsorption on WS under different temperatures (i.e., 298, 308, 318, and $328 \mathrm{~K}$ ) were calculated using the following equation $[43,44]$ :

$$
\begin{aligned}
K & =\frac{c_{s}}{c_{e}} \\
\Delta G & =-R T \ln K \\
\ln K & =\frac{\Delta S}{R}-\frac{\Delta H}{R T},
\end{aligned}
$$

where $K$ is the equilibrium constant, $c_{s}$ is the dye concentration adsorbed by the adsorbent at equilibrium $(\mathrm{mg} / \mathrm{g})$, and $c_{e}$ is the dye concentration remaining in solution $(\mathrm{mg} / \mathrm{L})$ at equilibrium. $\Delta H$ and $\Delta S$ values were obtained from the slope and intercept of linear Van't Hoff plots of $\ln K$ versus $1 / T$. Table 5 summarizes the values of the thermodynamic parameters for $\mathrm{MB}$ adsorption on WS particles.

The values of $\Delta G$ at different temperatures (298, 308, 318 , and $328 \mathrm{~K}$ ) were all negative, indicating the spontaneous nature of the adsorption process. The decrease in $\Delta G$ with increasing temperature showed that the adsorption was more favorable at room temperature $(298 \mathrm{~K})$. The value of $\Delta S$ was positive, indicating that there was a decrease in the randomness in the system solid/solution interface during the adsorption process. The enthalpy $(\Delta H)$ of the process was negative indicating that the adsorption was exothermic. Through the thermodynamic analysis, we concluded that the adsorption of $\mathrm{MB}$ onto walnut shell powder was favorable at room temperature. Our studies might have significant implications for industrial applications, as high removal efficiency of MB by WS particles can be easily achieved without any temperature control processes.

3.8. The Effect of Common Salt. The MB removal percentages (\%) were measured in the absence and presence of $\mathrm{NaCl}$ (i.e., 1, 5, and 10\%). As shown in Figure 7, in the absence of $\mathrm{NaCl}, \mathrm{MB}$ dye removal percentage (\%) at equilibrium can reach $98.2 \%$. By comparison, $\mathrm{MB}$ dye removal percentage (\%) at equilibrium decreased to $88.5 \%, 75.3 \%$, and $51.0 \%$ in the presence of 1,5 , and $10 \% \mathrm{NaCl}$, respectively. Therefore, we concluded that $\mathrm{MB}$ dye removal percentages decreased with the increasing of $\mathrm{NaCl}$ concentrations.

The different adsorption behaviors of MB dye on WS particles might be explained by the electrostatic forces between the WS particles and MB dyes. As discussed before, WS particles were negatively charged under our experimental conditions. In the presence of $\mathrm{Na}^{+}$, the surface charge of WS particles became less negatively charged. Therefore, less attractive forces existed between the less negatively charged WS particles and dye cations, resulting in less $\mathrm{MB}$ removal 

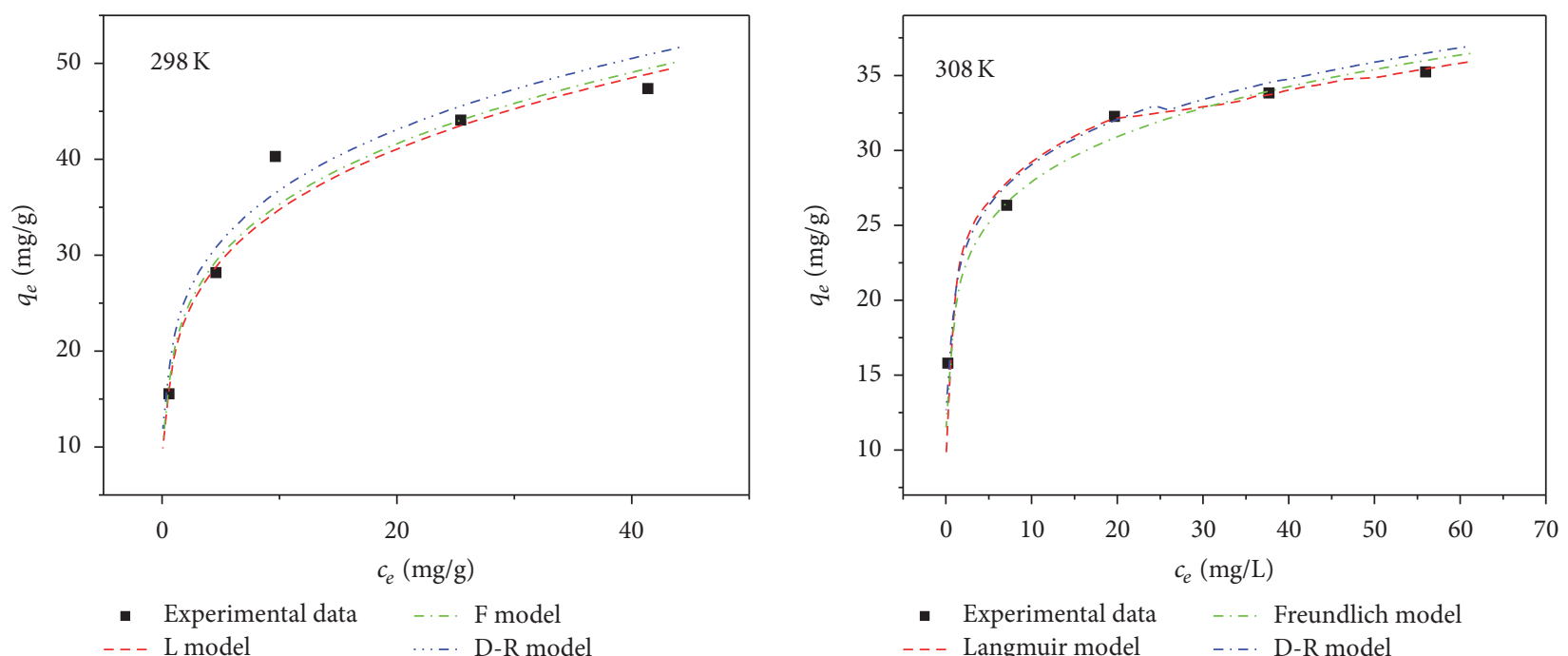

-.- L model _..... D-R model
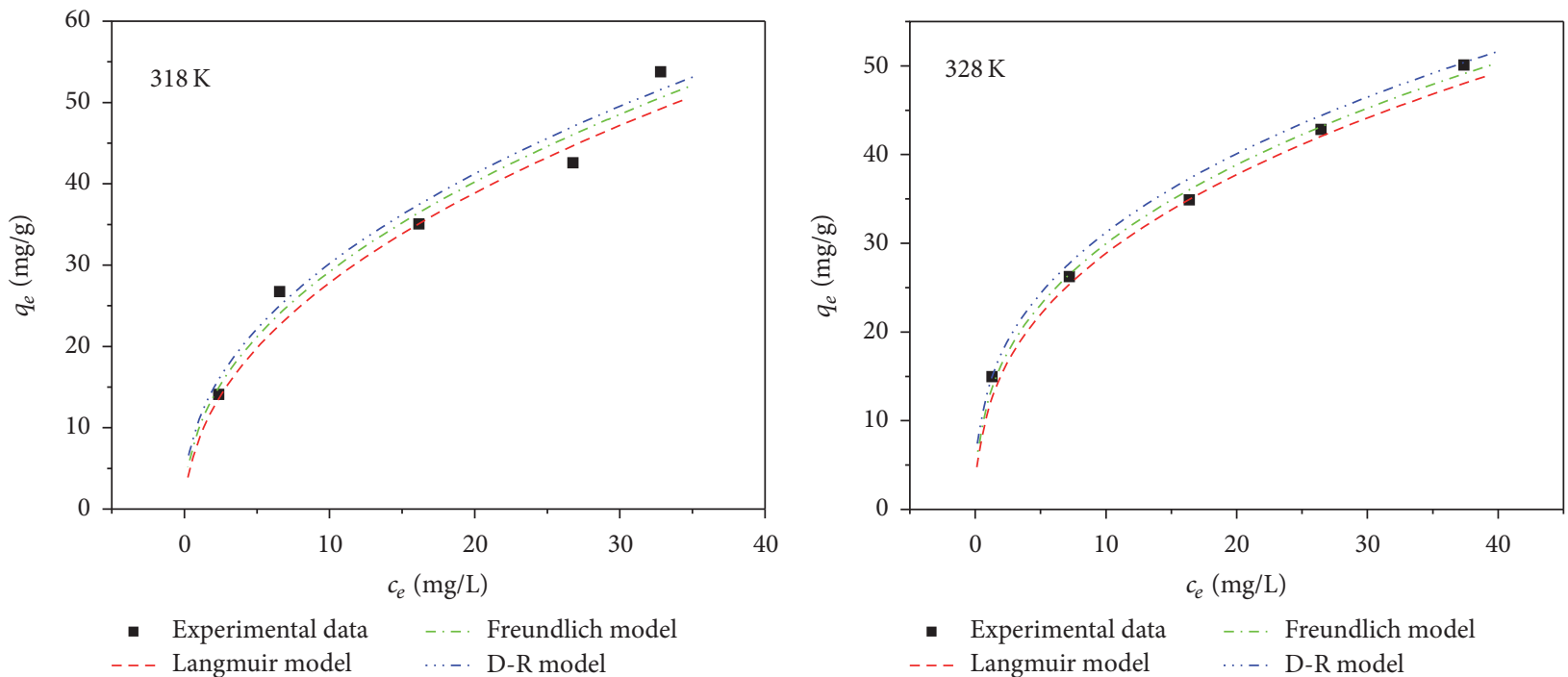

FIGURE 6: The adsorption isotherms at different temperature (i.e., 298, 308, 318, and $328 \mathrm{~K}$ ). The dash lines are the fitting curves of Langmuir, Freundlich, and D-R models.

percentages. Also, the presence of $\mathrm{Na}^{+}$ions can compete with the adsorption of dye cations on the active sites of WS, which resulted in the significant decreasing in MB removal percentages.

\subsection{Comparison of WS Adsorption Capacity with Other Adsor-} bents. The maximum adsorption capacity $\left(q_{\max }\right)$ of MB dye on WS can reach $51.55 \mathrm{mg} / \mathrm{g}$ under the optimal conditions (i.e., contact time $\sim 2 \mathrm{~h}, \mathrm{pH} \sim 6$, particle size $\sim 80$ mesh, and $1.25 \mathrm{~g} / \mathrm{L}$ adsorbent). Table 6 listed the maximum adsorption capacity $\left(q_{\max }\right)$ of some environmental-friendly and low-cost adsorbents for MB dye [25-29]. We found that the maximum adsorption capacity $\left(q_{\max }=51.55 \mathrm{mg} / \mathrm{g}\right)$ of $\mathrm{MB}$ dye on walnut shell (WS) was much higher than that of most of the lowcost adsorbents (e.g., orange peel, wheat shells, and rice husk), indicating that WS was a very promising and environmentalfriendly adsorbent.

\section{Conclusions}

Our study proposed to use an economic and environmentalfriendly walnut shell as the adsorbent to remove methylene blue for the first time. The effects of particle size, contact time, $\mathrm{pH}$, adsorbent dosage, and the concentration of salt $(\mathrm{NaCl})$ were investigated. By utilizing FTIR, the successful adsorption of MB on WS particles was confirmed to occur through functional groups. BET analysis showed that smaller particles have larger surface area than the bulk particles, resulting in more active adsorption sites, thus significantly improving the removal percentages. The solution $\mathrm{pH}$ was found to be a very important factor controlling the adsorption processes: the adsorption was favored under base conditions $(\mathrm{pH}>6)$. This can be explained by the electrostatic forces between WS particles and WB dyes. DLS results showed that WS surfaces were all negatively charged, while the surface of WS under base conditions was more negatively charged than under acidic 
TABLE 6: Comparison of MB adsorption capacity with some environmental-friendly adsorbents.

\begin{tabular}{lccc}
\hline Adsorbent & Dye name & Adsorption capacity $(\mathrm{mg} / \mathrm{g})$ & Reference \\
\hline Orange peel & MB & 18.6 & 68.03 \\
\hline Peanut hull & MB & 40.59 & {$[25]$} \\
Rice husk & MB & 39.84 & {$[27]$} \\
Cherry Sawdust & MB & 16.56 & {$[28]$} \\
Wheat shells & MB & 51.55 & This work \\
Walnut shell (WS) & MB & & \\
\hline
\end{tabular}

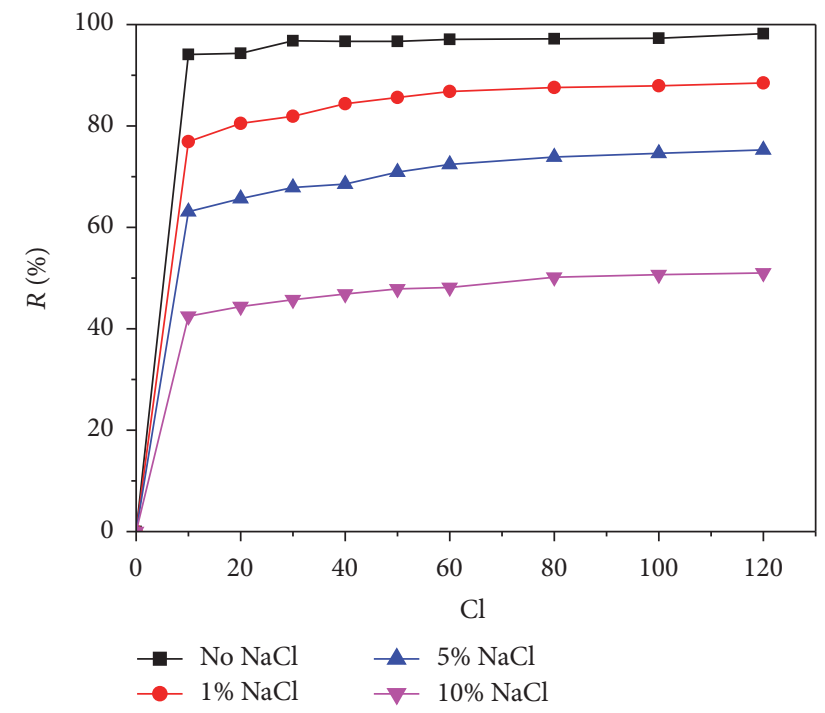

FIGURE 7: The effect of common salt $(\mathrm{NaCl})$ on the MB removal percentages $(R \%)$.

conditions. Therefore, under base conditions $(\mathrm{pH}>6)$, more attractive forces existed between cationic MB dyes and WS particles, resulting in more adsorption of $\mathrm{MB}$ on WS particles. The presence of $\mathrm{NaCl}$ was found to decrease the adsorption capacity of WS for $\mathrm{MB}$ due to the adsorption of $\mathrm{Na}^{+}$on WS particle surfaces. Under the optimized experimental conditions, the removal efficiency of $97.1 \%$ for MB by WS can be achieved, indicating that walnut shell was a promising and environmental-friendly adsorbent to remove cationic dyes.

To further understand the adsorption mechanisms, this study also systematically investigated the adsorption of $\mathrm{MB}$ on walnut shell from both kinetic and thermodynamic analysis. From the kinetic view, the rapid adsorption process fitted well with the pseudo-second-order kinetic model within the dye concentrations range investigated, indicating the adsorption process was a chemical adsorption. Intraparticle diffusion model showed that intraparticle was present but may not be the rate limiting factor. The positive correlation coefficient suggested that $\mathrm{MB}$ adsorption on WS could be best described by both the Langmuir isotherm $\left(R^{2}>0.97\right)$ and the Freundlich isotherm $\left(R^{2}>0.96\right)$. $\mathrm{D}-\mathrm{R}$ model also showed that the main mechanism for $\mathrm{MB}$ sorption was a chemical reaction. From the thermodynamic view, the adsorption process was spontaneous and exothermic. Meanwhile, the adsorption was favored at room temperature, which can be used in various industrial applications.

\section{Conflicts of Interest}

The funding did not lead to any conflict of interests regarding the publication of this manuscript.

\section{Acknowledgments}

This work was supported by the National Natural Science Foundation of China (no. 31671930), the Natural Science Foundation of Hebei Province (no. B2016204136), and the Program of Study Abroad for Young Teachers by Agricultural University of Hebei and Science \& Engineering Program by Agricultural University of Hebei (no. LG20150402).

\section{References}

[1] J. Duan, R. Liu, T. Chen, B. Zhang, and J. Liu, "Halloysite nanotube- $\mathrm{Fe}_{3} \mathrm{O}_{4}$ composite for removal of methyl violet from aqueous solutions," Desalination, vol. 293, pp. 46-52, 2012.

[2] J. Pierce, "Colour in textile effluents-the origins of the problem," Journal of the Society of Dyers \& Colourists, vol. 110, no. 4, pp. 131-133, 1994.

[3] V. Rocher, J.-M. Siaugue, V. Cabuil, and A. Bee, "Removal of organic dyes by magnetic alginate beads," Water Research, vol. 42, no. 4-5, pp. 1290-1298, 2008.

[4] G. Crini, "Non-conventional low-cost adsorbents for dye removal: a review," Bioresource Technology, vol. 97, no. 9, pp. 1061-1085, 2006.

[5] B. Gözmen, B. Kayan, A. M. Gizir, and A. Hesenov, "Oxidative degradations of reactive blue 4 dye by different advanced oxidation methods," Journal of Hazardous Materials, vol. 168, no. 1, pp. 129-136, 2009.

[6] A. N. Kagalkar, U. B. Jagtap, J. P. Jadhav, V. A. Bapat, and S. P. Govindwar, "Biotechnological strategies for phytoremediation of the sulfonated azo dye Direct Red 5B using Blumea malcolmii Hook," Bioresource Technology, vol. 100, no. 18, pp. 4104-4110, 2009.

[7] S. B. Jadhav, S. S. Phugare, P. S. Patil, and J. P. Jadhav, "Biochemical degradation pathway of textile dye Remazol red and subsequent toxicological evaluation by cytotoxicity, genotoxicity and oxidative stress studies," International Biodeterioration and Biodegradation, vol. 65, no. 6, pp. 733-743, 2011.

[8] D. K. Gardiner and B. J. Borne, "Textile waste waters: treatment and environmental effects," Journal of the Society of Dyers and Colourists, vol. 94, no. 8, pp. 339-348, 1978. 
[9] B. Li, Y. Hao, X. Shao et al., "Synthesis of hierarchically porous metal oxides and $\mathrm{Au} / \mathrm{TiO}_{2}$ nanohybrids for photodegradation of organic dye and catalytic reduction of 4-nitrophenol," Journal of Catalysis, vol. 329, pp. 368-378, 2015.

[10] K. S. P. Kalyani, N. Balasubramanian, and C. Srinivasakannan, "Decolorization and COD reduction of paper industrial effluent using electro-coagulation," Chemical Engineering Journal, vol. 151, no. 1-3, pp. 97-104, 2009.

[11] A. Thiam, E. Brillas, J. A. Garrido, R. M. Rodríguez, and I. Sirés, "Routes for the electrochemical degradation of the artificial food azo-colour Ponceau $4 \mathrm{R}$ by advanced oxidation processes," Applied Catalysis B: Environmental, vol. 180, pp. 227-236, 2016.

[12] P. Janoš, H. Buchtová, and M. Rýznarová, "Sorption of dyes from aqueous solutions onto fly ash," Water Research, vol. 37, no. 20, pp. 4938-4944, 2003.

[13] A. G. Espantaleón, J. A. Nieto, M. Fernández, and A. Marsal, "Use of activated clays in the removal of dyes and surfactants from tannery waste waters," Applied Clay Science, vol. 24, no. 1-2, pp. 105-110, 2003.

[14] A. Mittal, J. Mittal, A. Malviya, D. Kaur, and V. K. Gupta, "Adsorption of hazardous dye crystal violet from wastewater by waste materials," Journal of Colloid and Interface Science, vol. 343, no. 2, pp. 463-473, 2010.

[15] R. P. Han, P. Han, Z. H. Cai, Z. H. Zhao, and M. S. Tang, "Kinetics and isotherms of neutral red adsorption on peanut husk," Journal of Environmental Sciences, vol. 20, no. 9, pp. 10351041, 2008.

[16] K. Low and C. Lee, "The removal of cationic dyes using coconut husk as an adsorbent," Pertanika, vol. 13, no. 2, pp. 221-228, 1990.

[17] E.-K. Guechi and O. Hamdaoui, "Sorption of malachite green from aqueous solution by potato peel: kinetics and equilibrium modeling using non-linear analysis method," Arabian Journal of Chemistry, vol. 9, supplement 1, pp. S416-S424, 2016.

[18] V. Vadivelan and K. V. Kumar, "Equilibrium, kinetics, mechanism, and process design for the sorption of methylene blue onto rice husk," Journal of Colloid and Interface Science, vol. 286, no. 1, pp. 90-100, 2005.

[19] N. K. Amin, "Removal of direct blue-106 dye from aqueous solution using new activated carbons developed from pomegranate peel: adsorption equilibrium and kinetics," Journal of Hazardous Materials, vol. 165, no. 1-3, pp. 52-62, 2009.

[20] E. Lorenc-Grabowska, G. Gryglewicz, and M. A. Diez, "Kinetics and equilibrium study of phenol adsorption on nitrogenenriched activated carbons," Fuel, vol. 114, pp. 235-243, 2013.

[21] E. Pehlivan and T. Altun, "Biosorption of chromium(VI) ion from aqueous solutions using walnut, hazelnut and almond shell," Journal of Hazardous Materials, vol. 155, no. 1-2, pp. 378384, 2008.

[22] A. Almasi, M. Omidi, M. Khodadadian, R. Khamutian, and M. B. Gholivand, "Lead(II) and cadmium(II) removal from aqueous solution using processed walnut shell: kinetic and equilibrium study," Toxicological and Environmental Chemistry, vol. 94, no. 4, pp. 660-671, 2012.

[23] M. K. Dahri, M. R. R. Kooh, and L. B. L. Lim, "Water remediation using low cost adsorbent walnut shell for removal of malachite green: equilibrium, kinetics, thermodynamic and regeneration studies," Journal of Environmental Chemical Engineering, vol. 2, no. 3, pp. 1434-1444, 2014.

[24] J.-S. Cao, J.-X. Lin, F. Fang, M.-T. Zhang, and Z.-R. Hu, "A new absorbent by modifying walnut shell for the removal of anionic dye: kinetic and thermodynamic studies," Bioresource Technology, vol. 163, pp. 199-205, 2014.
[25] G. Annadurai, R.-S. Juang, and D.-J. Lee, "Use of cellulose-based wastes for adsorption of dyes from aqueous solutions," Journal of Hazardous Materials, vol. 92, no. 3, pp. 263-274, 2002.

[26] R. Gong, M. Li, C. Yang, Y. Sun, and J. Chen, "Removal of cationic dyes from aqueous solution by adsorption on peanut hull," Journal of Hazardous Materials, vol. 121, no. 1-3, pp. 247250, 2005.

[27] V. Vadivelan and K. Vasanth Kumar, "Equilibrium, kinetics, mechanism, and process design for the sorption of methylene blue onto rice husk," Journal of Colloid and Interface Science, vol. 286, no. 1, pp. 90-100, 2005.

[28] F. Ferrero, "Dye removal by low cost adsorbents: hazelnut shells in comparison with wood sawdust," Journal of Hazardous Materials, vol. 142, no. 1-2, pp. 144-152, 2007.

[29] Y. Bulut and H. Aydin, "A kinetics and thermodynamics study of methylene blue adsorption on wheat shells," Desalination, vol. 194, no. 1-3, pp. 259-267, 2006.

[30] C. Dai, A. G. Stack, A. Koishi, A. Fernandez-Martinez, S. S. Lee, and $\mathrm{Y} . \mathrm{Hu}$, "Heterogeneous nucleation and growth of barium sulfate at organic-water interfaces: interplay between surface hydrophobicity and $\mathrm{Ba}^{2+}$ adsorption," Langmuir, vol. 32, no. 21, pp. 5277-5284, 2016.

[31] Y. Hu, C. Neil, B. Lee, and Y.-S. Jun, "Control of heterogeneous $\mathrm{Fe}$ (III) (Hydr)oxide nucleation and growth by interfacial energies and local saturations," Environmental Science and Technology, vol. 47, no. 16, pp. 9198-9206, 2013.

[32] C. Dai and Y. Hu, "Fe(III) hydroxide nucleation and growth on quartz in the presence of $\mathrm{Cu}(\mathrm{II}), \mathrm{Pb}(\mathrm{II})$, and $\mathrm{Cr}(\mathrm{III})$ : metal hydrolysis and adsorption," Environmental Science and Technology, vol. 49, no. 1, pp. 292-300, 2015.

[33] C. Dai, X. Zuo, B. Cao, and Y. Hu, "Homogeneous and heterogeneous $\left(\mathrm{Fe}_{x}, \mathrm{Cr}_{1-x}\right)(\mathrm{OH})_{3}$ precipitation: implications for Cr sequestration," Environmental Science \& Technology, vol. 50, no. 4, pp. 1741-1749, 2016.

[34] Z. Bekçi, Y. Seki, and L. Cavas, "Removal of malachite green by using an invasive marine alga Caulerpa racemosa var. cylindracea," Journal of Hazardous Materials, vol. 161, no. 2-3, pp. 1454-1460, 2009.

[35] M. Arami, N. Yousefi Limaee, and N. M. Mahmoodi, "Investigation on the adsorption capability of egg shell membrane towards model textile dyes," Chemosphere, vol. 65, no. 11, pp. 1999-2008, 2006.

[36] A. B. Pérez Marín, M. I. Aguilar, V. F. Meseguer, J. F. Ortuño, J. Sáez, and M. Lloréns, "Biosorption of chromium (III) by orange (Citrus cinensis) waste: batch and continuous studies," Chemical Engineering Journal, vol. 155, no. 1-2, pp. 199-206, 2009.

[37] J. Liu, X. Wu, Y. Hu, C. Dai, Q. Peng, and D. Liang, "Effects of $\mathrm{Cu}(\mathrm{II})$ on the adsorption behaviors of $\mathrm{Cr}$ (III) and $\mathrm{Cr}(\mathrm{VI})$ onto kaolin," Journal of Chemistry, vol. 2016, Article ID 3069754, 11 pages, 2016.

[38] Y. Yao, F. Xu, M. Chen, Z. Xu, and Z. Zhu, "Adsorption behavior of methylene blue on carbon nanotubes," Bioresource Technology, vol. 101, no. 9, pp. 3040-3046, 2010.

[39] I. Langmuir, "The constitution and fundamental properties of solids and liquids. Part I. Solids," The Journal of the American Chemical Society, vol. 38, no. 2, pp. 2221-2295, 1916.

[40] H. Freundlich, "Over the adsorption in solution," The Journal of Physical Chemistry A, vol. 57, no. 385471, pp. 1100-1107, 1906.

[41] F. Helfferich, Ion Exchange, McGraw-Hill Book, New York, NY, USA, 1962. 
[42] C. Wang, C. Feng, Y. Gao, X. Ma, Q. Wu, and Z. Wang, "Preparation of a graphene-based magnetic nanocomposite for the removal of an organic dye from aqueous solution," Chemical Engineering Journal, vol. 173, no. 1, pp. 92-97, 2011.

[43] J. Romero-Gonzalez, J. Peralta-Videa, E. Rodriguez, S. Ramirez, and J. Gardea-Torresdey, "Determination of thermodynamic parameters of $\mathrm{Cr}$ (VI) adsorption from aqueous solution onto Agave lechuguilla biomass," The Journal of Chemical Thermodynamics, vol. 37, no. 4, pp. 343-347, 2005.

[44] E. Oguz, "Adsorption characteristics and the kinetics of the $\mathrm{Cr}(\mathrm{VI})$ on the Thuja oriantalis," Colloids and Surfaces A: Physicochemical and Engineering Aspects, vol. 252, no. 2-3, pp. 121-128, 2005. 

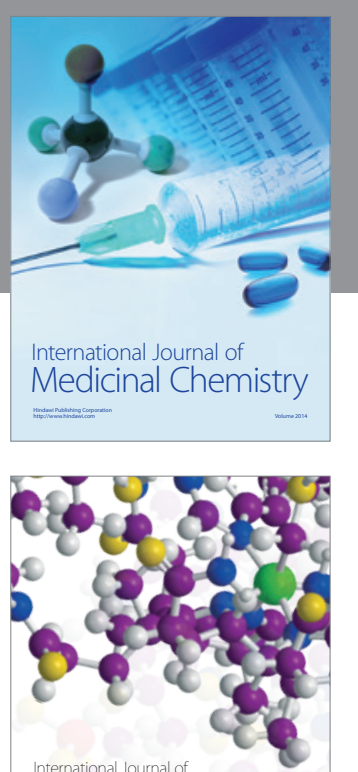

Carbohydrate Chemistry

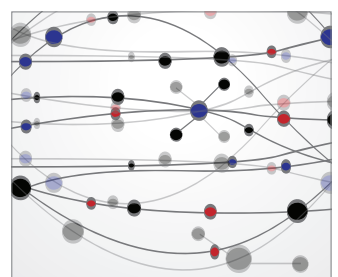

The Scientific World Journal
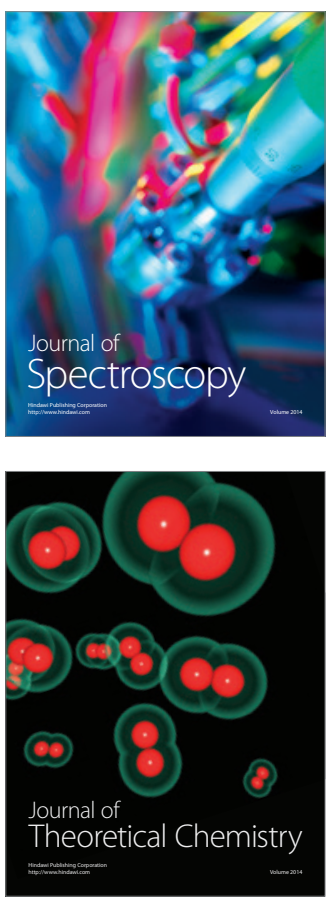
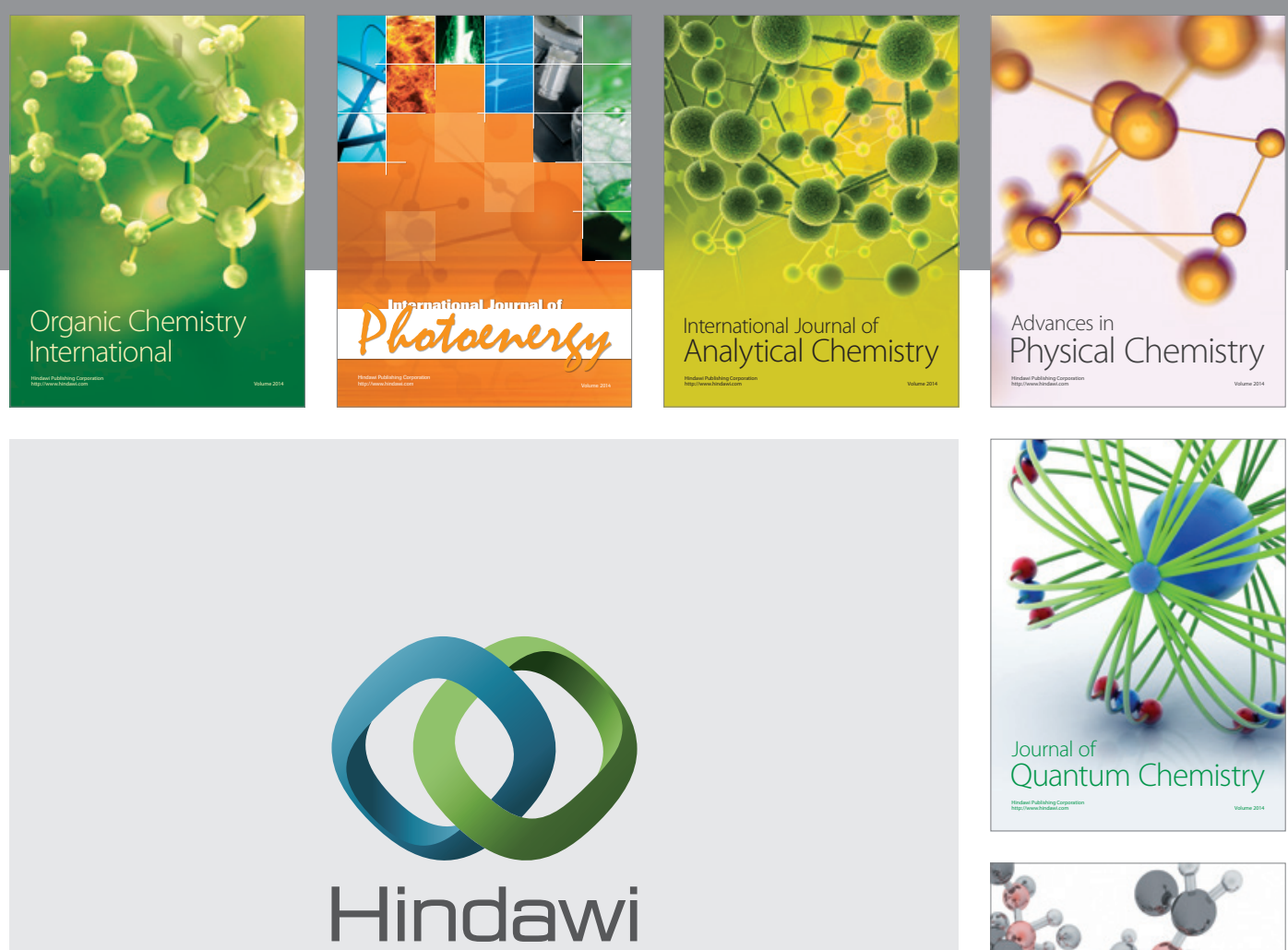

Submit your manuscripts at

https://www.hindawi.com

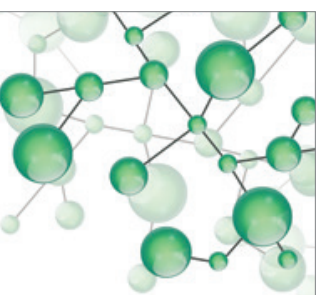

International Journal of

Inorganic Chemistry
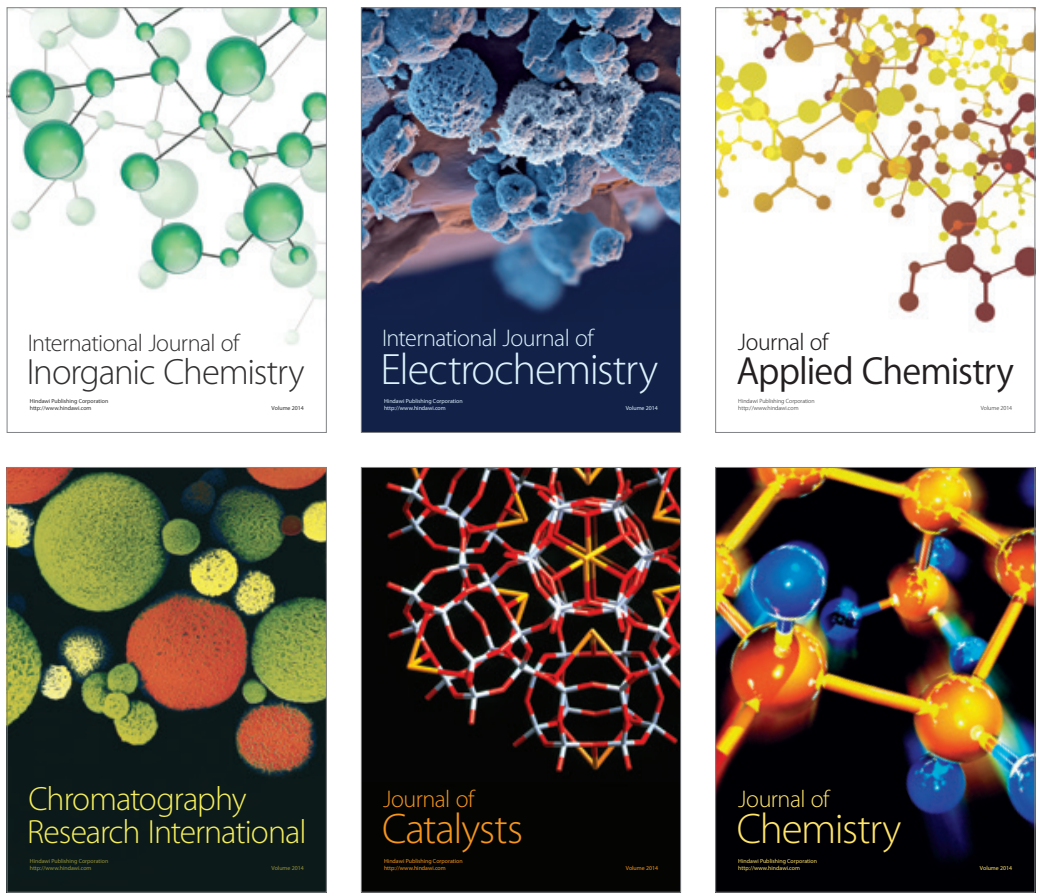

Journal of

Applied Chemistry
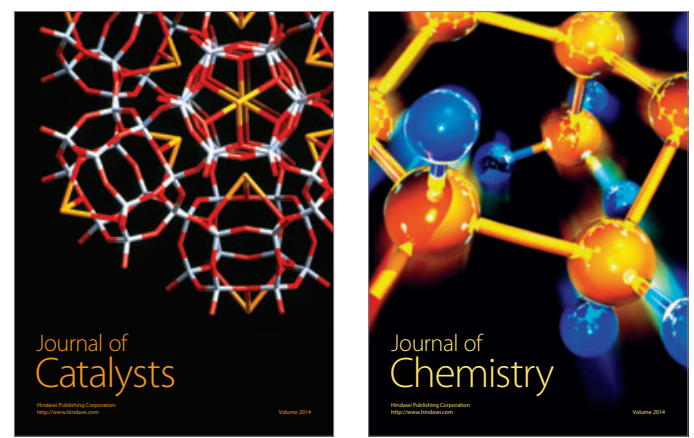
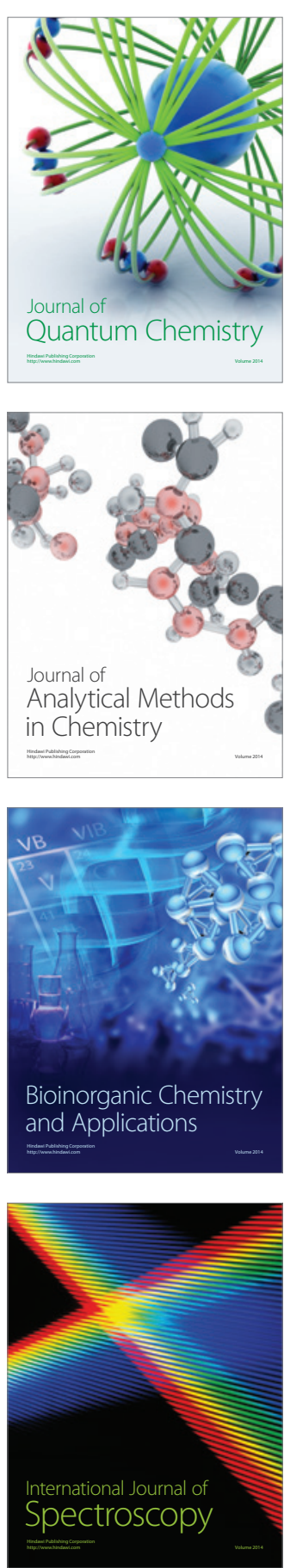